\title{
LA PRAXIS DE JESÚS COMO DESARROLLO DE SU IMAGINACIÓN AUTOCONSTRUCTIVA
}

\section{Algunos prolegómenos}

A diferencia de otros personajes históricos que nos legaron proverbiales escritos en los que ellos mismos sistematizaron su pensamiento a través de manifiestos, desarrollos especulativos o cualquier otro tipo de discurso escrito (eventualmente evaluables a la luz de testigos modernos, e incluso de los propios escritores), el nazareno no nos permite analizarlo con esa misma ductilidad. ¿Por qué habríamos de tomar a Jesús como un autor en el sentido tradicional? Este es un detalle importante a considerar si se quiere tener una percepción de Jesús en cuanto texto, no de terceros, sino de sí mismo. Este ensayo nos abre el juego a ese estudio.

Por eso tomaremos aquí a Jesús como autor, aunque no en el sentido que se aplica a los redactores de los mismos escritos desde los que hoy exudan sus palabras. Esa función sólo podría asignarse al colectivo social que construyó el orden de relatos presentes en cualquiera de los evangelios canonizados en el siglo II, e incluso aplicarse a los autores de otros evangelios descastados por la Iglesia. Sin embargo, mínimamente, nos encontramos frente al deber de reconocerle a Jesús la autoría de su propio discurso.

Jesús asumió para sí un rol construido siglos antes por los profetas hasta su contemporáneo Juan el bautizador, mediante un proceso hermenéutico de intertextualidad en el que se propuso leer las Escrituras junto con la situación histórica, política y religiosa de su pueblo bajo el 
sitio romano. Leyó las Escrituras bajo el reconocimiento de la condición humana universal, su propia persona e historia. ${ }^{1} \mathrm{Y}$ continuó leyéndolas en el marco de una concepción particular de la voluntad divina (calificable, claro está, de carácter subjetivo para unos, o inspirada para otros). Esta formulación nos conduce a una lectura cristológica que da pie a discutir si Jesús siempre fue Mesías, o si llegó a serlo por asumir el rol voluntariamente. La respuesta posiblemente polarice dos lecturas típicas de la encarnación: por un lado, un Jesús que se "viste" de ropas preparadas por "sastres ancestrales", para ser asumido y reivindicado como Hijo eterno por las comunidades. Por otro lado, la presunción al estilo medieval de que Jesús supo su mesianismo desde siempre, y por lo tanto, todas sus preguntas y avances con la gente pertenecerían a una dimensión pedagógica: Jesús sabía todo, pero hacía preguntas a la gente por el mero afán didáctico.

De lograr la resolución del prolegómeno inicial, es decir, el de plantearnos la autoría de Jesús sobre sí como dilema filosófico, de inmediato será liberada la intención de este trabajo: encontrar la huella del proceso hermenéutico ocurrido en la vida de Jesús que llega a constituirlo en el artífice de su praxis. Propondremos, entonces, que su propia persona debe ser interpretada como texto.

Pero ¿qué fuentes utilizar para encontrar este camino? Fundamentalmente, los escritos disponibles sobre su vida que enuncian dichos que para algunos biblistas serían ipsissima vox de Jesús (o, en todo caso, de ipsissima structura). ${ }^{2}$ Por un asunto de espacio y tiempo, sólo utilizaremos en este trabajo referencias a los evangelios canónicos. ${ }^{3}$ En este caso, para dedicarnos adecuadamente al objetivo central prescin-

1 A lo largo del artículo haremos referencia a lo "propio" de Jesús, tratando de señalar lo que es parte de su esencia en tanto persona, dato que tomará mayor sentido cuando apliquemos la idea de apropiación.

2 Entre Joachim Jeremias y John D. Crossan. Cf. por ej. J. D. CROSSAN, El nacimiento del cristianismo. Qué pasó en los años posteriores a la crucifixión de Jesús. Buenos Aires - EMECÉ - 2002; ID., Jesús, una biografía revolucionaria, Buenos Aires Planeta - 1996; J. JeREMIAS, Teología del Nuevo Testamento, I, Salamanca - Sígueme 1980; ID., Abba, el mensaje central del Nuevo Testamento, Salamanca - Sígueme $1983^{2}$

${ }^{3}$ En especial una reconstrucción de Q a partir de los sinópticos, y eventualmente sobre el evangelio de Juan. Otras fuentes podrían ayudarnos a completar el rompecabezas, como Hermas, la Didaché, el Evangelio de Pedro, Felipe o Tomás, e incluso la citación de fuentes como textos de Qumrán, 2 Macabeos, y otros; sin embargo, quedan para otro momento. 
diremos de las discusiones sobre la autenticidad, origen o antigüedad de los dichos registrados, temas a los que cualquier experto en las Escrituras podrá consagrar más tiempo. A esos efectos se admitirá que con las variantes posibles los logia jesuánicos -retocados por las comunidades o no- deben ser remitidos a Jesús de Nazaret, validando el contenido de los evangelios en función de nuestro trabajo. Recién allí podremos considerar a Jesús como autor en el sentido hermenéutico.

Nuestras afirmaciones en este ensayo serán de sesgo hermenéutico con arreglos teológicos, pero sobra decir que no podremos hacer este análisis si la vista se nubla con la figura de Jesús como objeto de la fe (cosa que tampoco se pone en discusión en este trabajo). Para que sea una tarea hermenéutica honesta, habremos de diferenciar una lectura fenomenológica del decir, pensar y hacer de Jesús, diseccionando de su figura, nuestra devoción.

Por último, trataremos de evitar la focalización de nuestra atención en terceros sujetos del texto, sino sólo en la imagen de Jesús. Para esto, se debe aclarar que el uso del término imagen que hacemos aquí, si bien resume un valor teológico, no responde al uso que se le otorga en la dogmática o en la teología clásica. Mientras que en los textos apostólicos y patrísticos el concepto imagen infiere el de imago Dei, como espéculo en el que Dios se refleja sobre el marco onto-teológico de la vida humana, aquí lo tomaremos sólo en el sentido lato, aplicándolo a la autocomprensión de Jesús (más cercano al recurso psicoanalítico de la estructura del Superyó).

Que nos concentremos en ese uso del concepto de imagen, se debe a que el proceso de la imaginación interviene con mucha fuerza en la vida humana como un instrumento heurístico capaz de inducir a la práctica profunda, retroalimentada con la ideología y la utopía. Tan grande es la fuerza de la imaginación que la construcción de la autocomprensión de Jesús proveerá más tarde un plus de sentido para otra comprensión relativa: una vida histórica de Jesús contada y escrita por los apóstoles y comunidades, que se convertirá en un marco de comprensión para sí mismas, unida a la proyección teleológica del cristianismo plasmada en su confesión.

Pero como fue dicho, aquí nos quedaremos sólo en un primer estadio de la autocomprensión más evidente en Jesús, apenas mencionando la transpolación de las historias de Jesús en evangelios orales y escritos. En cuanto leemos los dichos atribuidos a Jesús, vemos que 
indican claramente que él se adjudicó en forma pública un rol, fundado en la siguiente afirmación religiosa: reconocer que tiene una comisión de parte de Dios, cuyo alcance fue verificado en el contacto con sus contemporáneos. Pero, como el análisis de su discurso pertenece al terreno de los supuestos, es válido tomar recursos de la teoría hermenéutica de Paul Ricoeur como una vía posible para hacer una apuesta de sentido. Aquí nos interesa pensar lo que habría ocurrido en Jesús, en forma complementaria a lo que, generalmente, nos ofrece la investigación bíblica (aquello que habría sucedido con Jesús según el simple desarrollo de la trama en los evangelios).

Discutido el punto de partida del ensayo, a partir de una teoría general de la imaginación ricoeuriana, ${ }^{4}$ avanzaremos en tres etapas por el siguiente camino: daremos el primer paso analizando la relación entre imaginación e innovación semántica como el instrumental por el que Jesús se habría confrontado con los textos antiguos, con la vida cotidiana, y en ella, con el imaginario social. En un segundo momento, analizaremos la etapa de transición de la esfera teórica a la esfera práctica, en la que Jesús habría construido una imagen a través de la selección de las imágenes en los escritos proféticos. Por último, sobre la base de la retroalimentación entre el imaginario social y la tensión entre ideología y utopía, revisaremos la vida de Jesús y su praxis pública, que incluye la elección de un destino radical.

Pero para iniciar ese camino hay que establecer un jalón, que es reconocer la dimensión textual de Jesús, o dicho más sencillamente, Jesús como texto de acerca de sí.

\section{Jesús como autotexto}

¿Por qué partir de la suposición de que la existencia humana es como un texto? (o más aún, es un texto en sentido preciso). En primer lugar, cada ser humano encuentra esta existencia sometida a un extenso (aunque limitado) abanico de posibles significados. ${ }^{5}$ Comprender, y

${ }^{4}$ Tomo como base para esta propuesta el texto de P. RICOEUR, "La imaginación en el discurso y en la acción", Hermenéutica y acción, UCA/Prometeo - Buenos Aires 2008, 101-120.

5 Ricoeur llama a esta paradoja entre amplitud y limitación del significado una "plurivocidad específica". Ibíd., 73. 
particularmente comprender esos significados, es condición de la existencia humana y, en tanto la comprensión es una función hermenéutica, le acontece al sujeto como ejercicio de una capacidad natural. Ya no estamos frente a un simple dato epistemológico sino ante un rasgo ontológico, porque la interpretación de un texto conduce, según Ricoeur, "a la comprensión actual que un hombre puede hacer de sí mismo."” Allí donde el ser humano comprende, es donde ejerce mucho más que un modo de conocimiento: es donde el ser existe. Este comprender es $a$ priori de cualquier acto cognoscitivo, si se pone atención a Husserl, porque pertenece a la vida operante del sujeto. ${ }^{7}$ El ser humano es cuando comprende; nunca es más ser humano que cuando está atravesado por esa instancia, donde la comprensión de los signos que lo rodean y articulan la realidad se encuentra mediada por el lenguaje, lugar mínimo en que todos los seres humanos enuncian su interpretación del mundo circundante.

Por lo menos, nos es posible hablar del texto oral o el texto plasmado como de un alter ego del autor. Y si es posible hablar de la entidad del texto, también será posible hablar de la textualidad del ser, porque no existe palabra que no esté encarnada en cuanto constituye al lenguaje (y éste como constituyente de lo humano). ${ }^{8}$

Como sujeto en acción, el ser humano es "sujeto textual" pues su vida funciona como espacio de inscripción permanente. Como aquellos monumentos del pasado que nos cuentan historias en inscripciones o en las huellas del tiempo, de la violencia o del cuidado de algún curador, el ser humano también es sujeto textual. Esto es lo que convierte a las acciones humanas en acciones significativas. Incluso genera "la aparición de pautas que se convierten en los documentos de la acción humana", acciones que llegan a sufrir la solidificación interpretativa que deviene en instituciones. $^{10}$

En síntesis, la palabra se hace lenguaje, y la carne se hace persona humana. Y el lenguaje y la persona se significan mutuamente.

Entonces, considerar a Jesús como "autor" no parece hasta aquí un problema mayor. En cambio, sí cobra mayor importancia el hecho de que

\footnotetext{
${ }^{6}$ P. Ricoeur, Hermenéutica y estructuralismo, Megápolis - Buenos Aires - 1975, 8.

${ }^{7}$ Cf. Ibíd., 13.

${ }^{8}$ Cf. P. Ricoeur, El lenguaje de la fe, Megápolis - Buenos Aires - 1978, 145.

${ }^{9}$ Ricoeur, Hermenéutica y acción, 66.

${ }^{10}$ Cf. Ibíd., 67.
} 
le adjudiquemos la categoría de "texto acerca de sí", acto que se realiza en el plano autocomprensivo. Para ello, como cualquier persona, Jesús debe hacer un ejercicio de distanciación. Ricoeur explica esa dinámica:

\begin{abstract}
Al argumentar acerca del significado de una acción, pongo mis deseos y mis creencias a cierta distancia y los someto a una dialéctica concreta de confrontación con puntos de vista opuestos. Esta manera de colocar mi acción a distancia para comprender mis propios motivos prepara el terreno para el tipo de distanciamiento que se produce en el caso de lo que hemos llamado la inscripción social de la acción humana. ${ }^{11}$
\end{abstract}

Esta idea de "autoinscripción" basada en el paso previo de la distanciación, nos hace presente una teología del logos en la persona de Jesús (es decir, Jesús como palabra) cuya textualidad está autogestada, tanto desde las expectativas públicas, como desde su propia vocación. Allí participan las esperanzas culturales de la tradición y de sus convicciones personales, vale decir, de su propia teología. Jesús ejerce un movimiento de análisis deconstructivo que le conducirá a corregir la influencia individual de los referentes particulares (los otros actores históricos), pero al mismo tiempo, se dejará afectar sistémicamente por todos ellos a fin de establecer por innovación semántica un modelo nuevo y diferente.

He aquí otra faceta de su textualidad: la coherencia entre palabra y acción. En el cuerpo mismo de los textos del discurso de Jesús se encuentra presente, ante todo, un discurso sobre sí (además, claro, de la retroalimentación referencial con una comunidad redactora, que en ese ejercicio hace una confesión propia basada en el discurso de Jesús). Es un discurso que llegará a ser institucionalizado más tarde por la documentación en los evangelios orales y escritos que hoy en día nos brindan la fuente para nuestro análisis. Dicho de otro modo, en el acto de comprenderse, Jesús habla de sí jincluso cuando habla de temas exteriores a él! Por ejemplo, cuando relata una parábola u ofrece una enseñanza ética, está hablando (impersonalmente) de aquellas convicciones que son la síntesis y expresión de su ser y establece una identidad narrativa con su discurso. ${ }^{12}$ Igualmente, cuando la comunidad relata las historias de Jesús, también habla de sí misma.

11 Ibíd., 74.

12 Cf. M. YUtzIs, "Paul Ricoeur: una hermenéutica fenomenológica del sujeto. Aproximaciones", Cuadernos de Teología XXVII (2008) 267. 
Como criterio de textualidad, la vida de Jesús es objeto hermenéutico para sus contemporáneos, pero ante todo lo es para sí mismo. La diferencia entre la opinión del público exterior y la conciencia de Jesús es que, en cuanto al carácter intencional del discurso en un texto, Jesús mismo no se separa de su intencionalidad sino que está indisolublemente unido a ella.

El uso que Jesús hacía de las parábolas como recursos pedagógicos es de capital importancia en el fenómeno de la multivocidad de significados de los símbolos, que para Ricoeur poseen un rol predominante de "mostrar ocultando". ${ }^{13}$ Es cierto que el uso de parábolas era metodología común en la enseñanza rabínica, pero debe afirmarse que toda la vida de Jesús es una parábola que da origen a las otras parábolas, y como Palabra fundamenta todas las demás palabras acerca de sí. Jesús encarna su propio discurso, si es cierto lo que Ricoeur afirma sobre que todo formato de discurso religioso es instrumental a su propio contenido. ${ }^{14}$ Cualquiera de los discursos emitidos por Jesús en forma de parábolas o profecías coinciden en esto: el rol positivo de los personajes centrales (el mesías, o el padre amoroso, el pastor que encuentra la oveja, o la mujer que halla una moneda, etc.), responde a una forma de ser con la que Jesús acuerda decisivamente. Por lo tanto, aquella paradoja de mostrar ocultando se aplica en la existencia de Jesús. Como excurso sobre la tensión mostrar/ocultar, debemos también recordar el reclamo de silencio discreto a sus amigos frente a las manifestaciones mesiánicas, asunto sobre el que volveremos más adelante.

En cuanto a esta idea de textualidad, en esta etapa podríamos hablar de un Jesús que se halla en el transcurso de su propia escritura y de su propia interpretación, cosa que hace en simultaneidad con la interpretación exterior de sus contemporáneos.

\footnotetext{
${ }^{13}$ Cf. Ricoeur, Hermenéutica y estructuralismo, 17.

14 “La confesión de fe que se expresa en los documentos bíblicos está modulada directamente por las formas de discursos en las que se expresa". P. RicoeUR, Fe y filosofía. Problemas del lenguaje religioso, UCA/Prometeo - Buenos Aires - 2009, 150.
} 


\section{La deconstrucción de las esperanzas. Ante los referentes de la tradición y el pueblo}

El carácter textual distintivo de la vida humana está directamente vinculado a su capacidad imaginativa. No es posible definir, y definirse, sin la apertura que brinda el ejercicio de la imaginación. La imaginación será siempre el ámbito en el cual los mundos y las historias antiguas pueden cobrar un nuevo significado, un significado nuevo que se ejecuta por medio del lenguaje para dar así un atrevido salto de lo teórico a lo práctico. ${ }^{15} \mathrm{~A}$ este mecanismo Ricoeur llama innovación semántica.

Para que en Jesús tenga lugar tal innovación semántica es preciso que efectúe una evaluación, una verificación del estado del arte en cuanto a la necesidad real de una figura prometida por los profetas, o dicho en sus palabras, del cumplimiento del "año agradable del Señor" (Lc 4,19) vinculado al Jubileo. El plano hermenéutico nos permite advertir en Jesús la dimensión filosófica inscripta en su plena humanidad. Como ya se ha dicho, esto no es ni más ni menos que un mecanismo que le acontece a todo ser humano y, por eso, bien se puede decir que como sujeto hermenéutico, Jesús es un ser actuante (el Dasein husserliano).

Por lo tanto, comprender se transforma para él en una dinámica de retroalimentación: interpreta el mundo para comprenderse a sí mismo, pero se comprende a sí mismo para interpretar mejor al mundo a través del prójimo. ${ }^{16}$ Esa dinámica no tiene otro proyecto (y aquí usamos intencionalmente esta palabra) que conocer con más profundidad al otro. ${ }^{17}$ Sus encuentros con personas como Natanael (cf. Jn 1,47-50), Simón y Andrés (cf. Jn 1,39-39) o la mujer sirofenicia (cf. Mc 7,24-30), por poner unos pocos ejemplos, muestran ese interés de conocer al otro y darse a conocer como individuo.

Cuando Jesús se acerca a la gente se nota que para él la vida del pueblo no era un simple detalle informativo. Marcos indica que la razón por la que Jesús enseñaba al pueblo era que lo movía la compasión, pues

${ }^{15}$ Cf. RICOEUR, Hermenéutica y acción, 104.

${ }^{16}$ Este movimiento pautado en un caso concreto como el de Jesús, es similar al movimiento circular que Ricoeur halla constantemente en la díada entre la Fenomenología y el Psicoanálisis.

17 "Es (...) el ensanchamiento de la propia comprensión de sí mismo lo que persigue a través de la comprensión del otro". RICOEUR, Hermenéutica y estructuralismo, 21. 
los veía "como ovejas sin pastor" (Mc 6,34). Las múltiples sanidades y liberaciones están sujetas a ser formas de respuesta ante un estado de miseria que abarca todas las áreas de la vida humana, desde la falta de alimento, la enfermedad, la opresión socio-demónica de los poseídos, la alienación del pecado o la misma muerte. Y en tanto respuestas, son productos del acercamiento natural al pueblo desesperado, de un hombre que es -por lo menos- bueno. ${ }^{18}$

La tradición de Lucas muestra a Jesús preguntando a los discípulos por la opinión popular y la de ellos mismos, sobre a cuál de los personajes proféticos lo estarían asociando o identificando (cf. Lc 9,1820). Lucas usa la fórmula “¿quién dicen... que soy yo?” (Mateo ya hace una aplicación “i...que es el Hijo del Hombre?”). Aquí está presente, en un primer momento, la ipseidad de Jesús en medio de la tensión entre la distanciación y la apropiación. Busca saber cómo es visto, y saberse a sí mismo, a través de conocer al otro.

Pero Jesús no sólo se evalúa con el pueblo de la tierra. Los choques paradigmáticos entre Jesús y los representantes de los distintos poderes religiosos y políticos son mucho más que una pugna de intereses. Ricoeur nos recuerda que "las hermenéuticas más opuestas apuntan, cada una a su manera, en dirección de las raíces ontológicas de la comprensión" ${ }^{19}$ y esto es -ni más ni menos- una apuesta del ser.

Hasta aquí tenemos suficiente para decir que Jesús se interpreta a sí mismo frente a otros sujetos interpretantes: sus opositores claramente definidos, la gente del pueblo, los seguidores, o las Escrituras (estas últimas como símbolo del deseo divino). Por eso, lo que está en juego en las controversias de Jesús como conflicto de interpretaciones no son los intereses inmediatos ni las interpretaciones dogmáticas del judaísmo: lo que está en riesgo es el ser. Se trata de diferentes entidades en conflicto de interpretaciones, pero todas ellas provocadas por igual a dar cuenta de sí con algún grado de coherencia.

Debe ser mencionado también que su evaluación del ser ingresa en el terreno mismo de la espiritualidad. Es un poco difícil ir contra la

${ }^{18}$ Ruego al lector que no disminuya el valor de este adjetivo, que es de no poca amplitud. Sostengo que podría ser un perfil mínimo para Jesús, al menos como el joven rico lo diferenció: "maestro bueno" (Lc 18,18), virtud que Jesús remitió directamente a Dios.

19 RICOEUR, Hermenéutica y estructuralismo, 28. 
corriente tradicional que ve las acciones de Jesús (en especial en sus preguntas y conversaciones) como cierta pre-conciencia mesiánica. Frases como "conocía a todos (...) él sabía lo que había en el hombre" (Jn 2,25), "sabía (...) quienes eran los que no creían y quién le había de entregar" (Jn 6,64), y otras generalmente atribuibles a Juan (cf. 11,42; $13,11 ; 18,4)$ hacen más omnisciente al relator que a Jesús, a quien se le suele adjudicar esa percepción extrasensorial. Dicha omnisciencia queda en cuestión frente a una frase como la de Mc 13,32: "de aquel día y de la hora nadie sabe, (...) ni el Hijo, sino el Padre".

Sin negar algún tipo de presciencia en Jesús, propongámonos lidiar con esas preguntas y dudas de una forma diferente que hará relativa (y, no única) la clásica valoración retórica y didáctica de sus palabras. En tal caso, estas no habrían sido enunciadas únicamente en beneficio de los discípulos sino, en cambio, con el fin de calcular su propia persona frente a las circunstancias. Si esto es así, entonces varias preguntas de Jesús no establecerían certezas, sino más bien dudas razonables sobre la dirección a tomar. Deberían ser incluidos también en esta misma esfera los pedidos de afirmación divina: "Mi Padre me glorifica [confirma]" (Jn 8,54; cf. 17.1), “está turbada mi alma; ¿y qué diré? ¿Padre, sálvame...?” (Jn $12,27-28),{ }^{20}$ "si quieres pasa de mi esta copa, pero no se haga mi voluntad sino la tuya" (Lc 22,42).

Es preferible ver, entonces, una intención pedagógica bidireccional en Jesús -lo que hoy denominaríamos un proceso de enseñanzaaprendizaje- pero además una señal de vulnerabilidad en cuanto sujeto hermenéutico, y efectivamente coherente con su humanidad (tan olvidada en nuestro tiempo). La hipótesis incrementa su valor si se piensa que Jesús tiene una visión global, pero no acabada, de que el personaje que encarna debe sufrir la muerte por manos de su propia gente..$^{21}$ Por lo tanto, todo ensayo de prueba y error, o pedidos de confirmación divina (completado por los narradores con "es mi Hijo amado", Lc 3,22; 9,35) son condiciones que apuntan -preocupantemente para él- a verificar el desenlace fatal, y a garantizar que éste no fuera en vano.

${ }^{20}$ La confirmación viene de mano del narrador, en la boca divina "vino una voz del cielo (...) 'lo he glorificado, y lo glorificaré otra vez'."

${ }^{21}$ Cf. I. Ellacuría, "Por qué muere Jesús, y por qué le matan", Misión Abierta 2 (1977) $17-26$. 
Hasta aquí podemos identificar una primera etapa deconstructiva de evaluación, por la observación de la realidad. Podría ser explicada con mayor amplitud, pero al menos es bien identificable con el acto hermenéutico de "ver", donde Jesús se hallaría decidiendo que es necesario construir cierto modelo en el marco de hibridación que le presentan los distintos referentes. Pero, ¿qué modelo?

\section{La reconstrucción de una imagen inesperada. Transposición de la teoría a la praxis}

En esta etapa podríamos decir que Jesús se halla reorganizando todos los referentes del pasado y del presente, por lo cual es imposible simplificarla. En cambio, se deben buscar en ella círculos de comprensión más pequeños que contribuyan a la comprensión general y a la afirmación de una autoimagen particular. En un circuito de esta índole es mejor pensar que, en cuanto al arribo de un mesías, Jesús participaba de las mismas incertidumbres culturales del pueblo (aunque, tal vez, un paso más adelante por estar afectado objetivamente).

Detengámonos en un breve excurso. Los evangelios muestran este proceso en Jesús, pero no lo hacen como un desarrollo lineal. La única linealidad ocurre solamente en la mente de los narradores, que nos presentan esta trama desde el "no-saber" en dirección al "saber", porque ya tienen un esquema y un propósito que quieren anunciar. No debe extrañarnos, porque esta no-linealidad también ocurre a las personas incluso para las decisiones más simples de la vida. Por eso hallamos en las distintas escenas de las historias sobre Jesús una sucesión alternada de confirmaciones y dudas. Juan el bautizador, por ejemplo, aparece lleno de certeza al principio frente al bautismo de Jesús, pero ya en la cárcel tiene dudas sobre su mesianismo; dudas que reclaman confirmación (cf. Mt 11,3). Y Jesús también vivencia esta tensión duda/certeza, tal vez no sobre su mesianismo, pero sí sobre el tipo de ese mesianismo, porque lo que debe definir no es simplemente una respuesta a la pregunta "¿quién soy?”, sino a otra más riesgosa: “¿quién debo ser?”. Y en cuanto esta última pregunta quede respondida, a continuación seguirá otra más tremenda: la de ser muerto en manos de los ancianos y sacerdotes.

Para regular esta tensión, los evangelistas adoptan su propósito didáctico, y no dejan de controlar la dirección del relato para que los 
lectores no guarden dudas sobre la identidad de Jesús. Ahí es donde aplican la "tramposa" linealidad en el relato.

En cuanto a Jesús, hay cosas que parecen más claras que otras. Una de ellas es su sentido de misión. Si seguimos la orientación de Ricoeur, se podría decir que la comisión que Jesús asume estaría directamente relacionada con nombrar a Dios, por efecto de aquella distanciación operada en la innovación semántica; es al liberar a los textos sagrados de sus autores y destinatarios ${ }^{22}$ que Jesús se permite su propia poética. ${ }^{23}$ Pero ese nombramiento de Dios (es decir, su percepción de Dios para sí y para otros), continúa inscripta en aquella antigua "nominación de Dios por los profetas, los escritores, escatológicos y apocalípticos". ${ }^{24}$ Por lo tanto, nos encontramos con que Jesús no habla de Dios, sino sobre el Dios de los profetas, ${ }^{25}$ pero posee suma claridad acerca de cómo quiere verlo: como Padre bueno de todos y de todo. ${ }^{26} \mathrm{Y}$ esa perspectiva organiza su discurso.

Tal vez por el rasgo pneumático de su función y su carácter antihegemónico de fuertísima identificación con el pueblo, no sea difícil demostrar que los profetas veterotestamentarios son la referencia que enmarca esa misión de Jesús. De ellos es de donde toma elementos de la tradición sobre el Mesías, el Hijo del Hombre y el siervo sufriente de Yahvé. Jesús construye una hibridación basada en los tres personajes, desarrollando un modelo que él llama Hijo del Hombre y que posee el rango del Mesías esperado, pero que sufre las penalidades y muerte del Siervo de Yahvé. No podemos identificar cuánto de cada personaje está presente en su ideario personal, pero este modelo se define cada vez más en su historia, a medida que avanzan los conflictos con las estructuras representadas en instituciones y sujetos concretos, hasta donde será claro que el destino fatal es inminente, y en su ideario, también necesario.

Esta es una tarea concreta de innovación semántica a través de la que Jesús conviene en la adopción de una imagen. No se trata del mero cambio de sentido, sino de la "reestructuración completa de los campos

${ }^{22}$ Cf. Ricoeur, Fe y filosofía, 93.

${ }^{23}$ Cf. J. L. Espinel, La poesía de Jesús, San Esteban - Salamanca - 1986.

24 Ibíd., 102.

${ }^{25}$ Nota aparte, un reclamo al cristianismo de que debe hablar sobre el Dios de Jesús, y no "de Dios" en términos de dominio cognoscitivo.

${ }^{26} \mathrm{Cf}$. J. Jeremías, Abba, el mensaje central del Nuevo Testamento, Sígueme Salamanca $-1983^{2}$. 
semánticos", ${ }^{27}$ y por lo tanto, de un ángulo de abordaje diferente al tradicional. Por eso, de ninguna manera Jesús protege a la tradición per se sino que la revisa. Para Jesús, lo dicho por los profetas no está mal dicho, sino que propone la examinación de las interpretaciones de aquel discurso antiguo (Mt 5,17).

Aquí se debe abandonar, con la complicidad de Ricoeur, el concepto de imagen como representación mental privada, característicamente abstracta e inconexa con el mundo real que nos ofrece. Dicho esto, adherimos a una de las nociones de imaginación citadas por el autor como "representaciones que (...) se dirigen a cosas ausentes o inexistentes pero que (...) hacen creer en la realidad de su objeto". ${ }^{28}$ Una definición de esta índole permite establecer un vínculo concreto entre el mundo de las percepciones y el de la realidad donde la imaginación sirve como "instrumento mismo de la crítica de lo real". ${ }^{29}$

Si se aplica a Jesús, la cuestión que surge de inmediato es, ¿cuál fue su fuente previa de información para elaborar una imagen compleja de sí como la de este "Mesías-Siervo"? ¿Sobre qué tipo de experiencia sensible forjó esa autoimagen, si no hubo antes alguien semejante?

Una respuesta posible es que un imaginario social previo, presente en los profetas pero elucubrado entre la gente, le propuso a Jesús qué tipo de personaje era necesario encarnar. Se trataría de una "imagen poética", no de lo visto sino de lo dicho en los profetas y en el pueblo, en un claro círculo hermenéutico. ${ }^{30}$ Lo que no parece tan evidente es que Jesús tuviera una idea terminada del personaje que debía interpretar, aunque los testigos lo califiquen como "hijo de David" (Lc 18,38) o "hijo de Dios", por los prodigios y por su fidelidad al modelo de siervo ( $\sin$ la carga teológica que poseen las afirmaciones dogmáticas posteriores de Pablo o los padres apostólicos en cuanto Persona Trina).

Como ya fue mencionado, si se sostiene la textualidad de Jesús especialmente como "parábola de Dios", ${ }^{31}$ entonces predomina el ocultamiento en la mostración que son típicos en la metáfora. Esta paradoja es

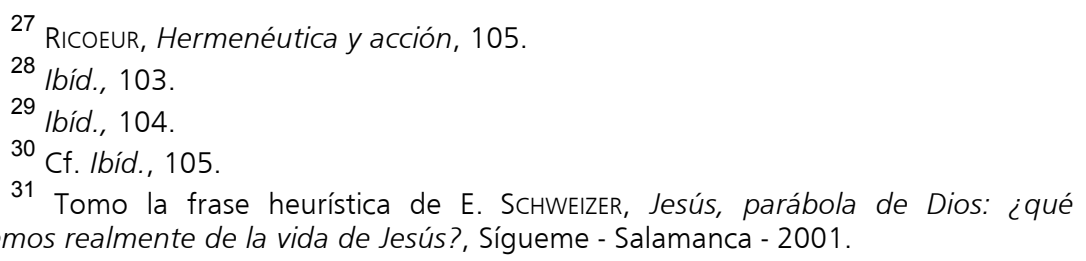


para Jesús una característica central del reino de Dios: mostrarse a los sencillos y nublarse ante los ojos de los expertos (cf. Lc 10,21). ${ }^{32} \mathrm{Un}$ ejemplo en la vida misma de Jesús de este mostrar ocultando se transluce en los relatos donde requiere de los testigos el llamado "secreto mesiánico" (cf. Mt 16,20; Mc 7,36; 9,9; Lc 8,56; 9,21) en cuyos casos, cuanto más rigor por sostener el perfil bajo y guardar silencio sobre su mesianismo, "tanto más lo divulgaban" (Mc 7,36).

La cristología en los inicios del siglo XX explicaría esa prudencia como el deseo de Jesús de señalar un tipo de mesianismo diferente al esperado (teoría razonable). Pero también es posible que Jesús evitara la formulación de un modelo específico postergado hasta la "manifestación" del Hijo del Hombre.

La cuestión es que, tratándose de personajes diferentes, el Mesías hijo de David, el Hijo del Hombre y el Siervo sufriente del Señor, también poseen diferentes niveles de autonomía en cuanto a su origen y misión. La categoría "mesías" responde más bien al envío divino. Pero sobre el Hijo del Hombre de Dn 7,13 (una figura de salvación universal) es donde Jesús hace afirmaciones que quiebran el estereotipo. ${ }^{33}$ Todos los eventos pronosticados para este Hijo del Hombre escatológico, suscriben en realidad al perfil del Siervo de Yahvé $^{34}$ caracterizado en varios poemas, particularmente en el de Is 52,13-53,12.

32 Para Ricoeur es "el hombre absorbido por su papel, y que la función social ocupa hasta el punto de volverlo indisponible para la sorpresa del encuentro". P. RicoeUR, El socius y el prójimo, Docencia - Buenos Aires - 1986, 9.

${ }^{33}$ En el bar 'ănašāh se mezclan las nociones de un "hijo de vecino" que representa a todos los demás seres humanos con el personaje de Dn 7. Como comisionado de Dios, Jesús afirma que este Hijo del Hombre se manifestará repentinamente e iniciará el juicio escatológico (cf. Mt 13,41; 19,28; 24,27-44; $25,13.31 ; 26,64)$, pero sufrirá a manos de los hombres representados en las jerarquías político-religiosas, y entregado por traición durante la Pascua para su crucifixión (cf. Mt $17,12.22 ; 20,18 ; 26,2.45)$. Es señor sobre la ley, es tolerante y viene para rescatar lo perdido. Pero, según él mismo, su muerte está bajo decreto de necesidad $($ Jn 3,14$)$.

${ }^{34}$ Cf. J. Jeremias, Teología del Nuevo Testamento, I, Sígueme - Salamanca - 1980, 320. Si bien está muy claro en los dichos de Jesús que la figura del Hijo del Hombre no está asociada a él (salvo en el salto hermenéutico de la comunidad), suscribimos a la propuesta de Jeremias de que la primera y la tercera persona están en el mismo plano, y que el núcleo de comprensión de Jesús no está en Daniel sino en Isaías. 
De su incertidumbre compartida ${ }^{35}$ con el pueblo deviene un segundo momento de claridad donde, bajo la nominación "Hijo del Hombre", es el Siervo sufriente del Señor el que aporta significación, mientras que Jesús les reclama a sus interlocutores que reconozcan lo que sucederá con el Mesías (¡como si para todos estuviera tan claro que el abanico de personajes se cruzan en uno solo!). Pues para Jesús ya ha comenzado a operar la objetivación a través de la distanciación ${ }^{36}-$ fenómeno determinante de cualquier texto- mientras se comprende a sí mismo en el entramado de las Escrituras y la realidad cotidiana.

Entonces, escribe su propio texto en un ejercicio de apropiación donde abandona toda "afinidad afectiva" con los referentes de ese entramado. El discurso y el personaje dejan ya de ser un proyecto de los profetas; ahora es propiedad de Jesús que ha optado quién quiere ser, y para qué. "Sé que ha de venir el Mesías (...) Yo soy, el que habla contigo" (Jn 4,25-26).

Dejaremos para la última sección el traspaso de la imaginación a la acción. Hasta ahora el análisis nos permite considerar una faceta reconstructiva en el círculo hermenéutico de Jesús, claramente apuntable en el nivel de "juzgar".

\section{Reactualización de la misión. Una praxis entre el imaginario social, la ideología y la utopía}

En esta sección nos abocaremos a discernir la resolución de un rol que refuerza la autoimagen de Jesús decidida según la dinámica reconstructiva de la sección anterior. Se trata de un movimiento hermenéutico en el que, por supuesto, se hallan actuando en forma simultánea todas las etapas de la comprensión. ${ }^{37}$

${ }^{35}$ Esta escatología errónea que aparece en Jesús fue compartida incluso por los primeros cristianos, como lo afirma G. THEISSEN - A. MERZ, El Jesús histórico, Sígueme Salamanca - 1999, 314.

${ }^{36}$ Cf. P. Ricoeur, "La función hermenéutica de la distanciación", en AA.VV. Exégesis, La Aurora - Buenos Aires - 1978, 246.

37 El dato de esta simultaneidad se ve en que cuando leemos los evangelios, podemos identificar alternadamente esas etapas en momentos diferentes de su historia. 
Al menos dos convicciones parecen estar firmes en la conciencia de Jesús según sus propias palabras. La primera, es la seguridad de que la intención divina es resguardar paternalmente la vida de los seres humanos (cf. Jn 12,50; 17,2-3). Este es un a priori en la elaboración de su autoimagen ${ }^{38}$ que coincide con la afirmación de Ricoeur de que la imagen es posterior a una significación emergente, ${ }^{39}$ pues "no vemos imágenes sino en la medida en que primero las entendemos". ${ }^{40}$ Aquí la imagen se encuentra a mitad de camino entre el significado y su concreción en el plano sensorial.

Dado que la imaginación es el componente que permite a un sujeto interrelacionarse "por transferencia (...) de la significación del yo", ${ }^{41}$ en el solapamiento natural entre los campos temporales de los distintos sujetos, esta relación histórica de la experiencia se convierte en el ambiente común en que "el otro es otro yo semejante a mí, un yo como 'yo". ${ }^{42}$ De modo que la segunda certeza de Jesús parece ser la necesidad de mantenerse abierto al encuentro con el otro, de quien él mismo ya es un prójimo. Nuestro filósofo afirma que

el lazo analógico que hace de todo hombre mi semejante solamente nos es accesible a través de una cierta cantidad de prácticas imaginativas, tales como la ideología y la utopía. ${ }^{43}$

Esta frase sugiere que la apertura a otro mundo mejor (es decir, orientado al bien, en cuanto es bien del prójimo y por ello también propio) está construida sobre la capacidad de vencer el miedo a la alteridad. No es "otro mundo" sino uno relacionado con el actual.

Dicha coparticipación o "acoplamiento" de campos temporales puede advertirse fácilmente en aquel relato del samaritano devenido en prójimo de un judío desconocido (cf. Lc 10,30-35). ${ }^{44}$ Justamente esto es lo que permite la continuidad histórica: una cadena inextricable de relaciones en tensión entre la apropiación y la distanciación. El otro conserva su subjetividad pero, en cuanto a la intersubjetividad, el otro

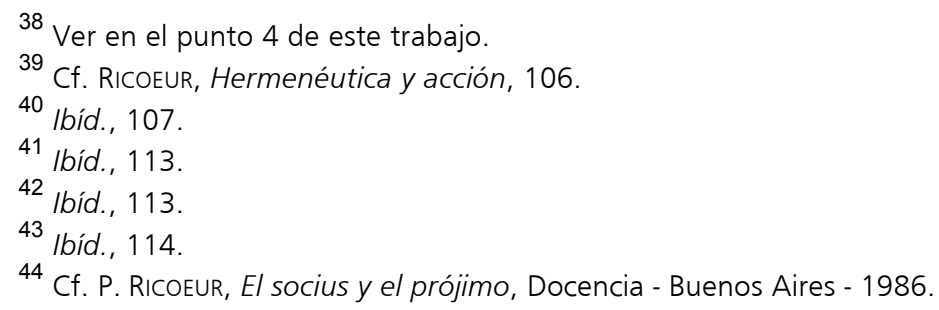


también me representa: es un "prójimo como yo mismo". Esta noción se hace presente en Jesús para articular la actualidad de su vida con el ideario de los profetas antiguos, pero también para articularse a sí mismo en la representación por todos sus hermanos. Si se quiere, también la parábola del juicio por el Hijo del Hombre en Mt 25,31-46 (particularmente los vv. 40 y 45), señalan esta representación.

Ambas certezas se encuentran ligadas por la tensión entre la ideología y la utopía. Ricoeur nos recuerda que “...la ideología parece ligada a la necesidad de un grupo cualquiera de darse una imagen de sí mismo, de "representarse"". ${ }^{45}$ Pero también es "un instrumento de legitimación de la autoridad. (...) todas las utopías, en algún momento, vienen a ofrecer otras maneras de ejercer el poder". ${ }^{46}$

Bajado del plano filosófico al terreno doméstico, Jesús sostiene su confianza en la tradición (como ideología), pero sabe también que la institucionalidad es capaz de tornarla en instrumento de muerte. ${ }^{47}$ Por eso, debe ser regulada por la esperanza vital de un futuro distinto que está proyectado en la utopía. Así, ideología y utopía no pueden considerarse simplemente antagónicas, sino que se hallan en una tensión insuperable, y en vistas de su capacidad de corregirse mutuamente, Ricoeur afirma la importancia de dicha tensión para evitar una lectura "cuasi-patológica". ${ }^{48}$

Ahora bien, si es cierto que "en lo imaginario es donde pruebo mi poder de hacer, donde mido el 'yo puedo"”, 49 entonces la imaginación es la fuerza referencial necesaria para sostener la utopía, y por eso también para reducir el miedo natural al destino. Frente al sino, Jesús permanentemente pone en palabras lo que ha de sucederle -ique ya ha sido escrito!- aún cuando sólo intuye la conspiración de los religiosos que traman su muerte. Pero junto con eso, lleva al ámbito del lenguaje el otro mundo posible, como mecanismo de redescripción de la realidad y como fuerza heurística para rehacerla. ${ }^{50} \mathrm{Al}$ iniciar su proyecto lee en la sinagoga de su pueblo una profecía de liberación ("hoy se ha cumplido

\footnotetext{
45 Ricoeur, Hermenéutica y acción, 115.

46 Ibíd.

${ }^{47}$ Ver punto 3 de este trabajo.

48 RICOEUR, Hermenéutica y acción, 117.

49 Ibíd., 111

${ }^{50}$ Cf. Ibid., 108.
} 
esta Escritura delante de ustedes”, Lc 4,21), y al aplicarla a sí mismo, rompe los límites que suele levantar el miedo al poder de la tradición.

La praxis de Jesús está impregnada por estas certidumbres. Incurriríamos en un error al suponer que Jesús elaboró su imagen en el clásico estado de aislamiento que pretenden algunas teorías de revelación (e incluso sólo en los últimos tres años). Si Jesús nació y vivió como un galileo pobre, siendo testigo de los abusos policiales romanos y de la manipulación religiosa, así como de la devoción de un campesinado capaz de entregarse sin condición para agradar a Dios... Y, si como discípulo de Juan el bautizador (como afirma Theissen) fue identificado por aquel como su sucesor $-\mathrm{y}$ con dotes superiores en cuanto al cumplimiento de la voluntad divina- recibiendo el traspaso de la misión de Juan desde una celda de detención (de la que su maestro saldría sólo para morir decapitado)... Y, si todo esto ocurría con la anuencia de los sectores ortodoxos de la religión, cabe una sola pregunta: ¿cómo esperar que estos eventos no tuvieran influencia en la formación de su propio perfil hermenéutico?

Sin necesidad de licencias oficiales, Jesús recompone la tradición secuestrada bajo una interpretación alienante (cf. Mt 5,21-28) y, al revelar la vulnerabilidad de las instituciones judías, detona un complot para capturarlo. Pero la nota central es que para Jesús ya está abierta la posibilidad de un mundo distinto, aunque la inminencia de la muerte se haga presente en el horizonte. Porque su imagen de sí ya está corroborada con todos los referentes y puede decir que él mismo es aquel de quien el texto bíblico había hecho referencia. En este momento sabe cuál es el paso próximo: "De un bautismo tengo que ser bautizado, y ¡cómo me angustio hasta que se cumpla!" (Lc 12,50); y "es necesario que se cumpla todavía en mí aquello que está escrito: 'Y fue contado con los inicuos'; porque lo que está escrito de mí, tiene cumplimiento" (Lc 22,37). La misma idea volverá a ser levantada por el autor de Hebreos al citar el Salmo 40,7: "He aquí vengo; en el rollo del libro está escrito de mí".

Ahora, Jesús es libre para la praxis radical desde su propio interior.

\section{Cerrando el círculo hermenéutico}

En el transcurso de este ensayo se ha intentado desarrollar la siguiente hipótesis: que Jesús tuvo su propio proceso hermenéutico (y con 
ello, epistemológico, teológico, emocional, espiritual, etc.) a fin de decidir quién era y qué era lo que debía hacer en función de esa identidad. A través de viñetas de los relatos sobre Jesús y sus dichos, se lo observa discerniendo su mundo y su lugar en la historia humana, decidiendo si las figuras bíblicas y las expectativas populares le permitían (o no) llevar a cabo lo que él entendía como comisión divina, para concretarse en una figura elaborada eclécticamente con consecuencias de praxis radical. Claramente verificamos el movimiento circular de "verjuzgar-actuar".

Según nuestra interpretación de los dichos, Jesús arma una agenda de correspondencia con las figuras rescatadas de los textos antiguos: a) clarifica su objetivo; b) coteja los pasos de la misión con las figuras que los textos le proponen; c) la experiencia le devuelve similitud con los textos (en especial sobre rechazos y disensión con las jerarquías; aprobación y recepción por el pueblo de la tierra); d) detecta los odios y la lucha de poder (el relator, como narrador omnisciente, nos cuenta del complot para matarlo); e) Jesús pide comprobaciones de la compañía divina y reaseguros del proyecto; y f) va hacia la muerte bajo esa convicción, no accidentalmente ni contra su voluntad, sino como la última instancia de afirmación de su textualidad.

En el ciclo completo se translucen elementos de la teoría hermenéutica de Paul Ricoeur. Se puede establecer la textualidad de la vida, la distanciación con los referentes y la apropiación del discurso, la innovación semántica como expresión de cambio y la afirmación de la identidad narrativa del sujeto con su discurso en medio del conflicto de las interpretaciones.

Esta lectura hermenéutica de la vida de Jesús (a sabiendas de que existirían múltiples significaciones posibles) no se agota en sí misma; es sólo una sistematización que nos permite corroborar la aplicabilidad de la teoría hermenéutica ricoeuriana, y que además señala un camino para hablar del ajuste que se produce entre la fundamentación teórica y las prácticas vitales de Jesús.

La consideración de este proceso resulta en una herramienta útil a los fines de revisar los pequeños pero magnos relatos que componen la agenda de las luchas sociales, o el mapa histórico del cristianismo. Por ejemplo, en la vida de los mártires de todas las épocas: ¿Qué es lo que lleva a una persona a aceptar el seguimiento de Jesús estableciendo el 
nombramiento de Dios - con todo lo que eso conlleva- como prioridad por encima de la vida propia?

Al menos esta parece ser una deuda pendiente del análisis bíblicoteológico: la de la exploración de la interioridad de los personajes en cuanto proceso hermenéutico en los casos de teología biográfica.

GUILLERMO STEINFELD

Buenos Aires - Argentina

guillermosteinfeld@hotmail.com 